\title{
Successful management of HIV infection in a patient with ulcerative colitis; a case report
}

\author{
Zain Majid ${ }^{(\mathbb{D}}$, Shoaib Ahmed Khan, Hina Ismail, Nishat Akbar, Rajesh Mandhwani, Nasir Luck \\ Department of Hepato-gastroenterology, Sindh Institute of Urology and Transplantation, SIUT, Karachi, Pakistan
}

Correspondence to:

Zain Majid,

Email:Zain88@hotmail.com

Received: 8 Mar. 2021

Accepted: 13 June 2021

ePublished: 20 Aug. 2021

Keywords: Ulcerative colitis, HIV virus, Mesalamine, Tumor necrosis factor alpha

Citation: Majid Z, Ahmed Khan S, Ismail H, Akbar N, Mandhwani R, Luck N. Successful management of HIV infection in a patient with ulcerative colitis; a case report. J Prev Epidemiol 2021;6(1):e17. doi: 10.34172/jpe.2021.17

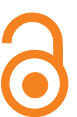

\begin{abstract}
Human immunodeficiency virus (HIV) is an infectious disease that is rarely seen in ulcerative colitis patients. Both diseases commonly involve the colon. It has been shown that treating these patients with anti-tumor necrosis factor (anti-TNF) therapy leads to remission of both conditions. We hereby present the case of a 7-year-old boy who was initially managed as a case ulcerative colitis after undergoing extensive workup and later on tested positive for HIV infection and was managed via mesalamine and highly active antiretroviral therapy (HAART). Mesalamine therapy along with HAART can be used to treat ulcerative colitis patients infected with HIV infection in resource limited countries.
\end{abstract}

\section{Introduction}

Ulcerative colitis is a type of inflammatory bowel disease that can involve the large intestine. It has several extra-intestinal manifestations along with a number of associated conditions (1). The human immunodeficiency virus (HIV) infection commonly affects the gastrointestinal (GI) tract and GI symptoms are evident in half of these patients (2).

\section{Case Report}

A 7-year-old boy presented to our outpatients' department having a history of low-grade fever along with an increase in his stool frequency since 2 weeks. He had a prior history of chronic diarrhea two years ago, for which he underwent upper and lower gastrointestinal endoscopies multiple times.

The patient had a significant past medical history of pulmonary tuberculosis, at the age of 2.5 years, for which he was treated for 10 months with anti-tuberculosis therapy (ATT). His developing history was unremarkable and he had achieved all his milestones on time. His parents had a consanguineous marriage. His last upper and lower GI endoscopies were done two years ago at a local tertiary care center, biopsies of which had revealed the following findings; in the esophagus a mild chronic inflammation with superficial erosions was noted since sloughed cells presented separately with fungal spores and hyphae, which was

\section{Key point}

Our case report showed that HIV infection can be seen in ulcerative colitis patients and timely treatment of both leads to improvement in symptoms. Our case highlights the successful use of the first line agents for ulcerative colitis when seen with HIV infection.

suggestive of probably candidiasis. In the duodenum, moderate chronic duodenitis was seen along with partial villous atrophy. In the descending and sigmoid colon chronic active inflammation with gland distortion, patchy goblet cell depletion, few crypt abscess formation and focal cryptitis were noted, all of which were suggestive of ulcerative colitis.

The boy had been managed on the lines of ulcerative colitis and was given oral antifungal therapy for his candidiasis.

On admission, his loose stool was episodic, small in amount, occurring 10 times per day, associated with crampy abdominal pain and tenesmus. They were found to be mixed with blood as well as mucus. His fever was of low grade, undocumented, not associated with rigors or chills, having no specific time of occurrence and was relieved by syrup Paracetamol. For these complaints, he was admitted to a nearby hospital, where he was managed symptomatically and one packed cell was transfused at that time.

On examination he appeared emaciated, anemic, dehydrated, having clubbed fingernails. Poor oral hygiene and dentition

Copyright $\odot 2021$ The Author(s); Published by Society of Diabetic Nephropathy Prevention. This is an open-access article distributed under the terms of the Creative Commons Attribution License (http://creativecommons.org/licenses/by/4.0), which permits unrestricted use, distribution, and reproduction in any medium, provided the original work is properly cited. 
was noted along with a few herpetic lesions evident on his lower lips.

Laboratory reports were normal apart from a low platelet count $(68 \times 109 \mathrm{fl})$, low albumin $(2.6 \mathrm{~g} / \mathrm{dL})$ and a MCV of $53 \mathrm{fL}$. His ESR was raised $74 \mathrm{~mm} / \mathrm{h}$. His stool detail report along with culture and sensitive were unremarkable while cytomegalovirus (CMV) polymerase chain reaction (PCR), tissue transglutaminase (TTG serology), antineutrophil antibodies (ANCA) were all negative.

Based upon the Truelove and Witt's criteria and a pediatric ulcerative colitis activity index of 40 , he was diagnosed as a case of ( mild to moderate) ulcerative colitis, with a disease extent up to the descending colon and was started on mesalamine (Asacol) along with mesalamine (Asacol) enema and sulphasalazine. Acyclovir was also given for herpes labialis and was later discharged.

During this time, he was seen by ENT (ear, nose, and throat) physician for an ulcer like lesion in his palate which was diagnosed as mucormycosis (Figure 1). Due to the lack of improvement in his symptoms, his HIV serology was sent and it came out to be positive having a CD4 count of 300 cells per cubic millimeter of blood. Later on his parents were also tested and his mother was found to be HIV positive.

He was started on highly active antiretroviral therapy (HAART) (lamivudine, tenofovir, nevirapine) therapy, pneumocystis carinii pneumonia, Mycobacterium avium complex prophylaxis (azithromycin, trimethoprim/ sulfamethoxazole) IV (intravenous) amphotericin 50 mg OD (once every day), IV ganciclovir $50 \mathrm{mg}$ OD and hydrocortisone enema, Asacol enema for his ulcerative colitis (due to the lack of available of anti-tumor necrosis factor (TNF) therapy and its higher cost). He had significant improvement in his symptoms within a month and was kept on regular follow up for both conditions.

\section{Discussion}

HIV infection in a patient with ulcerative colitis is rarely found and diagnosing both conditions can be difficult since both commonly affect the colon (3). Immunological factors are thought to play a role when both diseases occur together (4) with the CD4 cells playing a minor role in the pathogenesis of ulcerative colitis (5). Inflammatory bowel disease (IBD) is manifested as having an aggressive immune response while HIV results in a lessened immune response in the gastrointestinal tract, leading it vulnerable to opportunistic infections (6). HIV infection can either improve the symptoms of an IBD patient or could cause a relapse, with the occurrence of new disease when there is a decline in CD4 count (4). A prospective study done comparing 20 IBD patients having HIV with patients who had IBD alone, found a relapse rate of 0.016 episodes per year in the HIV group compared to 0.053 in the control group (7).

Treatment with TNF alpha is safe for patients with IBD having ulcerative colitis $(5,6)$. As for the use of

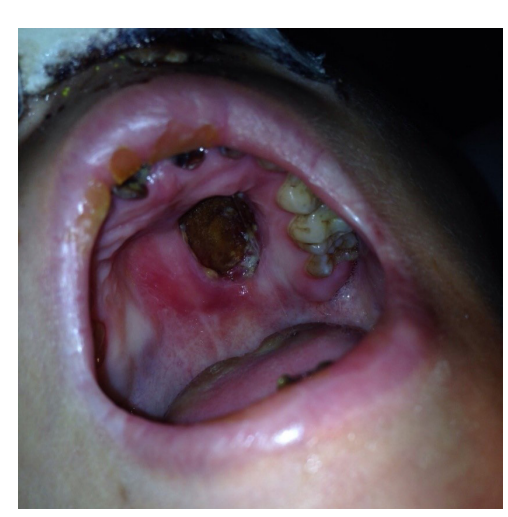

Figure 1. The evidence of a large necrotic area around $2 \mathrm{~cm}$ in size which was subsequently removed to reveal an ulcerated area suggestive of mucormycosis

immunomodulators, data is still in its early stages.6 Habib et al demonstrated the use of infliximab in treating Crohn's disease in a patient with HIV infection who was not on HAART therapy (8). Data on the use of azathioprine in this patient population is limited (6).

\section{Conclusion}

This case showed that HIV infection could be seen in ulcerative colitis patients and timely treatment of both leads to improvement in symptoms. Our case highlights the successful use of the first line agents for ulcerative colitis when seen with HIV infection.

\section{Authors' contribution}

ZM wrote the first draft of the manuscript and managed the patient. NA managed the patient. SAK and $\mathrm{HI}$ wrote the second draft. RM wrote the initial draft and contributed with the images. NHL corrected and edited the final version.

Conflicts of interest

The authors declare that they have no competing interests.

\section{Ethical considerations}

Ethical issues (including plagiarism, data fabrication, double publication) have been completely observed by the authors. Informed consent was obtained from the parents of patient for publication of this report.

Funding/Support

None.

\section{References}

1. Ulcerative Colitis: Practice Essentials, Background, Anatomy [Internet]. Emedicine.medscape.com. [Cited 18 June 2020]. Available from: https://emedicine.medscape.com/ article/183084-overview.

2. Bhaijee F, Subramony C, Tang SJ, Pepper DJ. Human immunodeficiency virus-associated gastrointestinal disease: common endoscopic biopsy diagnoses. Patholog Res Int. 2011;2011:247923. doi: 10.4061/2011/247923.

3. Kawaguchi T, Sako M, Yoshimura N, Takazoe M, Ryu T. A case of. HIV infection associated with ulcerative colitis. Nihon Shokakibyo Gakkai Zasshi. 2009; 106(4):536-541. 
4. Adiga A, Panikkath D, Nugent K. A Review of Inflammatory Bowel Disease in Patients with Human Immunodeficiency Virus Infection. J AIDS Clin Res. 2016;7:575. doi: 10.4172/21556113.1000575.

5. Bernstein CN, Snape WJ Jr. Active idiopathic ulcerative colitis in a patient with ongoing HIV-related immunodepression. Am J Gastroenterol. 1991;86:907-9.

6. Mendoza JYP, Ponce de León CE, Hernández CG, Beltrán OA, Varón PA, Garzón MA, et al . A Case Report of Severe Ulcerative Colitis in an HIV Patient. Rev Col Gastroenterol.
2016:31:433-7.

7. Viazis N, Vlachogiannakos J, Georgiou O, Rodias M, Georgiadis D, Papastamopoulos V, Baraboutis IG, Karamanolis DG, Skoutelis A. Course of inflammatory bowel disease in patients infected with human immunodeficiency virus. Inflamm Bowel Dis. 2010;16:507-11. doi: 10.1002/ibd.21077.

8. Habib SF, Hasan MZ, Salam I. Infliximab therapy for HIV positive Crohn's disease: A case report. J Crohns Colitis. 2009;3:302-4. doi: 10.1016/j.crohns.2009.06.002. 